Fecha de recepción: diciembre 2018 Fecha de aceptación: marzo 2019 Versión final: abril 2019

\section{George E. Street y el Gothic Revival}

Fabián S. López Ulloa *

Resumen: George E. Street (1824-1881) es considerado uno de los máximos diseñadores del Gothic Revival durante el esplendor económico del Reino Unido en la época victoriana junto a G. G. Scott, W. Butterfield, o W. Burges y, representó a través de su prolífica obra, una época cargada de simbolismo en torno a un estilo canónico de marcado acento religioso que Pugin consideraba como un ideal de nación. Y por tanto, estuvo sujeto a opiniones que defendían por un lado el sentido purista en el manejo del estilo, relacionado solo con la influencia del gótico inglés, y por otro lado, el que además incluía la influencia continental relacionada con el resto de Europa. Un estilo que no solo tenía que ver con el estricto sentido de su aplicación a una obra nueva, sino también en cómo se lo aplicaba en las innumerables reformas, ampliaciones y restauraciones del cual fueron objeto infinidad de edificios góticos. En esa medida la presente investigación se adentra en los recursos estilísticos manejados por George E. Street y, cómo su obra se consagró no solo en el ámbito del diseño arquitectónico sino también en el diseño de muebles y accesorios.

Palabras clave: Gothic Revival - George E. Street - Restauración Gótica - Arquitectura Gótica - Morfología.

[Resúmenes en inglés y portugués en las páginas 29 - 30]

(*) Doctor Internacional por la Universidad Politécnica de Madrid (UPM). Máster en Estructuras de la Edificación y Arquitecto Superior por la UPM. Máster en Restauración y Rehabilitación del Patrimonio por la Universidad de Alcalá. Especialista en Restauración y Rehabilitación Arquitectónica por la Universidad Libre de Bruselas - Universidad Central del Ecuador (UCE). Docente e Investigador de la UPM y la Universidad Técnica de Ambato.

\title{
Introducción
}

El Gothic Revival ha sido definido como un estilo ecléctico, debido a la combinación o fusión de un repertorio formal y tipo morfológico de prácticamente todos los recursos estilísticos del gótico europeo, en donde ya no solo determinados elementos de diseño servían para un típico propósito -normalmente edificios religiosos-sino que se usaban o 
adaptaban a cualquier tipo de espacio, así como también a otras formas o soluciones estructurales, combinadas con la utilización de nuevos materiales, propios de la revolución industrial.

La canon en el manejo del Gothic Revival llevará a Pugin ${ }^{1}$ a ser el abanderado de su causa, cabe decir que será su principal defensor, el más purista, promulgando su difusión como un ideal de nación.

El alto gótico victoriano es un término impreciso. Gran parte de la arquitectura de inspiración gótica de la mitad de la época victoriana era colorida, exuberante y ricamente escultórica, aunque las mejores obras de los diseñadores de iglesias más experimentados y considerados de los años 1850 -George Frederick Bodley, William Burges, William Butterfield, Pearson, Street- se caracterizaron por tener un énfasis en paredes ininterrumpidas, techos planos y volúmenes geométricos simples, manifestados maravillosamente en torres con cubiertas a dos aguas o en agujas piramidales, así como en algunos planos de pared continuos discurriendo alrededor de un extremo absidal curvado (Stamp, 2003, p. 197).

La restauración arquitectónica en la época victoriana tuvo mucho auge relacionado con el esplendor económico británico, entendida como una forma de intervención que pretendía modernizar las antiguas estructuras góticas y construir otras desde cero, todo a partir del Gothic Revival, lo que suponía también una fuerte carga teórica que se vio avivada con los principales actores de la escena arquitectónica inglesa.

La discusión iniciada en el siglo XIX en torno a la restauración arquitectónica ha pasado a la historia principalmente con nombres como Viollet-le-Duc, Ruskin, Morris o Pugin, pero detrás de ellos se reconoce a una serie de personajes de toda filiación que fueron desarrollando y conjugando la teoría y la práctica científica que ya apuntaba sus orígenes en las postrimerías del siglo XVIII en la iniciada República Francesa (López, 2010).

Para dar una visión general de los acontecimientos que envolvieron a George E. Street (Ver Figura 1) en la disciplina de la restauración arquitectónica en la Inglaterra del siglo XIX, basta recordar que con la reina Victoria se había afianzado el poder de la nación como potencia mundial industrializada y, que como tal, se sucedieron hechos trascendentales que afectarían a su desarrollo en todos los órdenes, quedando con el apelativo de victoriano no solo la época misma, sino que derivaría entre otros al arte, a la economía, a la literatura y por supuesto a la arquitectura, con el Gótico Victoriano, el Alto Gótico Victoriano, o el Gótico Tardío Victoriano, en suma, tendencias del Gothic Revival, verdadera esencia del culto de un reino que con dicha arquitectura monumental y ante todo de carácter religiosa, quería demostrar su preponderancia en el mundo y que llegaría a materializarse incluso en grandes proyectos fuera de Inglaterra. ${ }^{2}$

Para completar sus estudios del gótico, una tradición iniciada por Willis, ${ }^{3}$ Street emprendió sus propios viajes arqueológicos por varios países europeos, siendo significativos los viajes realizados a Italia y España de los cuales en un lapso de diez años compiló suficiente material para publicar dos de sus más afamados libros, uno sobre el gótico italiano titulado Brick and Marble in the MiddleAges, (Street, 1855), y otro sobre el gótico español bajo el título Some Account of Gothic Architecture in Spain, (Street,1865). 


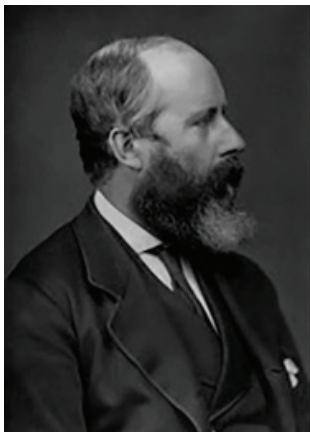

Figura 1. G. E. Street, 1871 (Street, 1888)

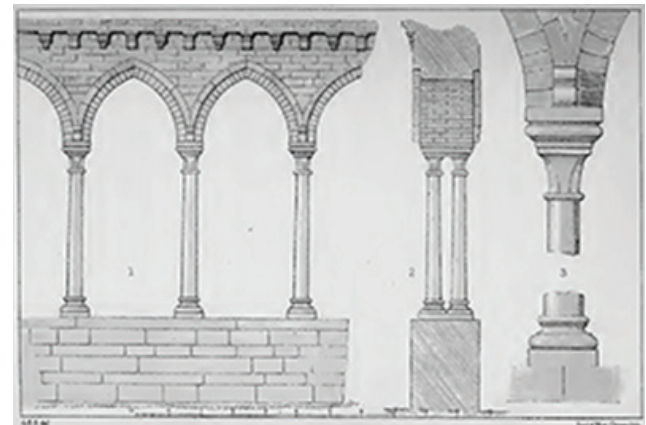

Figura 2.Verona, detalles del claustro de San Zenone, dibujo de G. E. Street (Street, 1855)
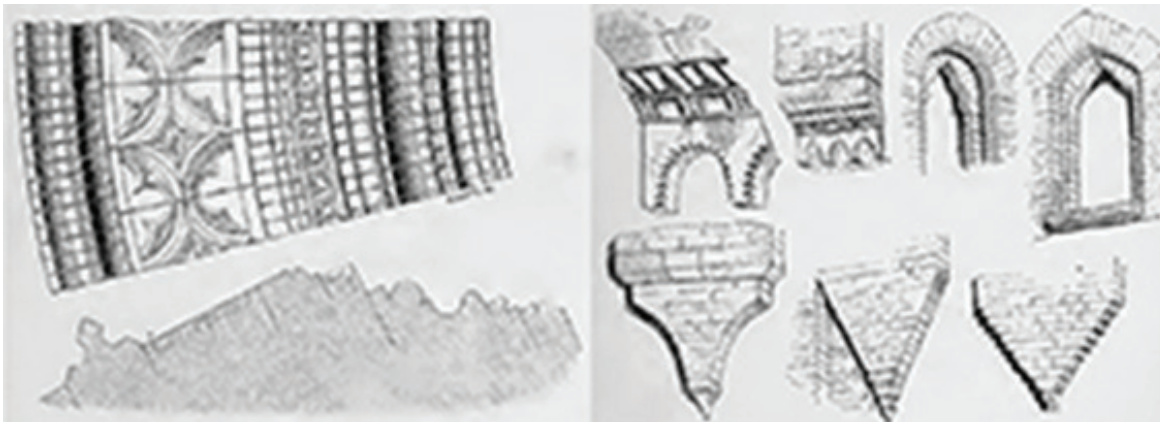

Figura 3. Italia, detalles de ventanas y cornisas para chimeneas, dibujos de G. E. Street (Street, 1855)

A través del libro sobre Italia, Street dio a conocer las variaciones o novedades constructivas, destacando sobremanera el uso y disposición de muros y bóvedas de fábrica de ladrillo y mármol (Ver Figuras 2 y 3), sobre lo cual Savorra sostiene:

Estudiada como la principal fuente de formas clásicas y góticas estratificadas, la arquitectura y las ciudades italianas están descritas, y por lo tanto, representadas por Street a través de una imagen coral y al mismo tiempo idealizadas. El carácter urbano refleja el sentido colectivo: el repertorio de detalles, formas y técnicas sobre las cuales el libro mora ampliamente, revela a los ojos del viajero británico una armonía y un equilibrio entre el espacio y la arquitectura, entre la visión y la percepción, entre el conectivo urbano y los monumentos. Entre los valores espirituales y las obras en piedra se crea una perfecta consonancia, una obra del reconocido artista y del artesano anónimo, que son los arquitectos de un orden superior (Savorra2006, p. 392). 
En cuanto al libro sobre España entre otras cosas incluyó como novedad varias plantas arquitectónicas (Ver Figura 4), haciendo un recuento de gran parte de la arquitectura gótica española "con una suerte de ilustraciones en las que además de representar a detalle la arquitectura, introdujo: figura humana, esculturas, mobiliario, elementos litúrgicos, vegetación, y tantos otros de la vida cotidiana" (López, 2009, p. 790), pero se echó en falta alguna sección o corte, que por su parte si incluyó en el libro de Italia.

La obra de Street tuvo pues una enorme influencia en España, gracias a la novedad de las herramientas metodológicas utilizadas, a la capacidad de enmarcar la arquitectura que veía en el más amplio contexto del gótico europeo, así como las distintas etapas que se superponían en el edificio, y a su forma de interpretar directamente "in situ" los rasgos formales y constructivos. Pero su impacto se debía también de manera muy significativa, a la calidad y cantidad de sus dibujos que, al servicio de esta forma de ver la arquitectura, poseían e introducían rasgos novedosos en la cultura gráfica española (López y Girón, 2014, p. 439).

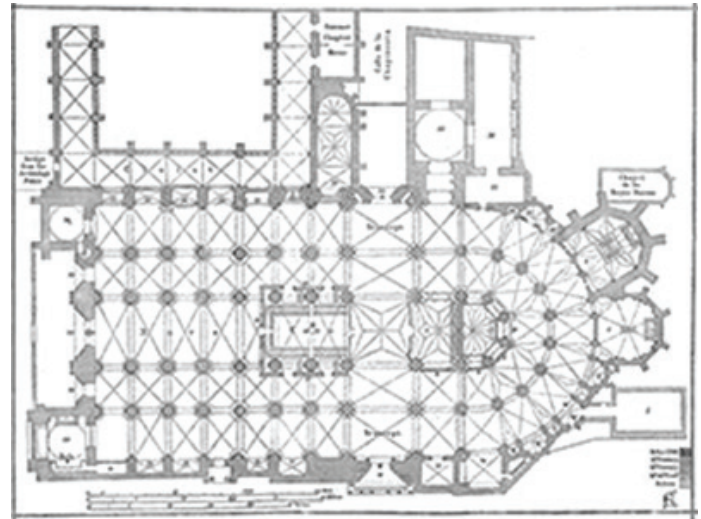

Figura 4. Toledo, planta de la catedral, dibujo de G. E. Street (Street, 1865)

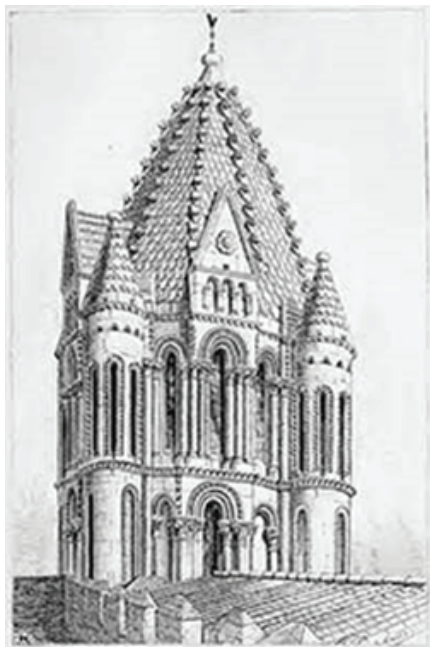

Figura 5. Salamanca. Catedral vieja, cimborrio, fachada oeste (Street, 1865)

\section{Los valores morfológicos en la obra de Street}

La habilidad de Street para leer las obras arquitectónicas le dio los suficientes argumentos para patentizar sus análisis en su obra gráfica y arquitectónica. En el caso de España se 
le atribuye el hecho de ser el primer arquitecto que a través de sus viajes arqueológicos compiló el hecho arquitectónico gótico de gran parte de los edificios españoles, de ahí los valores por él rescatados o descubiertos en el diseño gótico español.

Para Street, el hecho de encontrarse mayoritariamente con obras sin una historia de restauraciones, le permitió tener una visión arqueológica de cada una de ellas para profundizar en su historia constructiva, ya que hasta entonces no había tenido informes exactos y fidedignos en cuanto a su verdadero estilo, época o historia (López, 2011, p. 777).

En cuanto a las variaciones o adaptaciones del estilo y sobre todo a la permeabilidad estructural del gótico para solucionar algunas condicionantes formales, dio a conocer por ejemplo algunas soluciones encontradas en España, señalándolas por un lado como primicias del estilo en su conjunto del gótico europeo (Ver Figura 5), y por otro como ejemplos de adaptabilidad formal, que a lo largo de los siglos se esparcieron por Europa.

$\mathrm{Al}$ respecto por ejemplo, cabe señalar su observación hecha en Salamanca en donde le llamó la atención el cimborrio de la antigua catedral del S. XII y que da forma a la conocida como Torre del Gallo, cuya solución dada a la bóveda tras elevarla sobre el tambor, con el resultado de ventanales de gran luminosidad, marcaba una originalidad nunca antes vista en una construcción gótica. (López, 2009, p. 797).

Ésta serie de descubrimientos afianzó su teoría y práctica profesional respecto a un estilo que Pugin había venido gestando en contraposición al Neoclasicismo y Roma, y que a través de su libro Contrasts (Pugin, 1836), lo dejó señalado diciendo que dichos estilos estaban asociados con el Protestantismo y la Reforma, y anunciando el renacimiento de los verdaderos estilos católicos de la Edad Media. Entre otros aspectos a ser considerados por Street para dar preferencia al gótico, estaba su adaptabilidad.

En gran medida, no hay razón alguna para que la arquitectura gótica no se prefiera a otra, especialmente en el caso de las plantas, ya que permite satisfacer cada necesidad de una manera más natural y sencilla. No está atada por ninguna presunta necesidad de regularidad de sus partes o igualdad de divisiones, sino que cuando es necesario, satisface a menudo ciertas irregularidades (Street, 1853,p. 73).

El valor morfológico dado por Street a su obra se sustentó en el hecho estructural gótico que indicó se dio a partir del aparecimiento del arco apuntado, el cual fue usado en todo tipo de edificios medievales, señalando que sin embargo de lo cual, sus arquitectos contemporáneos al parecer lo reproducían casi exclusivamente en edificios religiosos, tratando de ocultarlo en el resto de sus obras. A través un artículo en la revista The Eclessiologist ${ }^{4}$ hace el siguiente señalamiento respecto al arco apuntado: 
Por muchos principios simbólicos que haya tenido el estilo gótico con formas y arreglos particulares, sus principales características fueron claramente constructivas, y surgieron mediata o inmediatamente a partir del aparecimiento del arco apuntado. Los edificios antiguos en verdad lo prueban. En los siglos XIII y XIV los huecos apuntados de puertas y ventanas no siempre se usaban solamente en edificios religiosos, al contrario, el arco apuntado se usó constantemente en todo tipo de edificios, creo que fue por mucho, el mejor principio de construcción que conocían los arquitectos de entonces. En nuestro caso es igual, sabemos que no hay nada mejor para aguantar el peso de los grandes muros que el arco apuntado, y por lo tanto debemos usarlo donde sea; por lo que no puedo apreciar ni comprender los principios o el estado de ánimo particulares que pueden caracterizar a cualquier arquitecto que utilice y haga énfasis del uso del arco apuntado solo en sus obras eclesiásticas, evitando cuidadosamente toda apariencia de familiaridad con éste, en el resto de su obra civil (Street, 1853, p. 72).

Una vez que Street diera a conocer las otras posibilidades de diseño del gótico manejadas fuera del Reino Unido, su devenir en las manos de sus coetáneos discurrió con una fuerte carga pintoresca y romántica, incorporándose una serie de elementos del gótico, del románico y del renacimiento sin importar su función original o sus posibilidades estructurales. ${ }^{5}$ Y a la estructura de la edificación es a la que Street le otorgaba un valor indiscutible para la ejecución de sus obras, sobre la base de la tradición en las técnicas constructivas empleadas y asimismo en el tradicional comportamiento de los materiales, que prácticamente seguían siendo los mismos a lo largo de los siglos transcurridos desde que apareció el estilo gótico. Sobre lo cual indicó:

Debo asumir hasta que no vea demostrado todo lo contrario, que no hay ninguna razón para que los mismos principios de edificación, no deban ser aplicados en la construcción de todos los edificios donde se utilicen materiales similares (Street, 1853, p. 73).

Un valor que lejos estuvo de ser seguido por algunos de sus más conspicuos colegas, sobre todo por la incorporación del acero estructural a la industria de la construcción, el cual ofrecía nuevas posibilidades de diseño, y aunque sin desmerecer su uso, había puesto al servicio del Gothic Revival a los más variados diseños y a los más insospechados edificios, entre los que se podían contar: grandes museos, tiendas comerciales, monumentos, puentes, estaciones ferroviarias, edificios administrativos, palacetes privados $\mathrm{u}$ hoteles, como por ejemplo el monumental Midland Grand Hotel de Londres (Ver Figura 6).

De hecho los arquitectos que alcanzaron mayor notoriedad, materializaron el estilo con nuevas estructuras, cabe decir, con nueva tecnología y opciones de diseño con más impacto, con un fuerte sentido comercial y de espectáculo, cuyas obras a día de hoy siguen llamando la atención por su fuerte expresividad, su colorido y su monumentalidad, como por ejemplo el Tower Bridge de Londres (Ver Figura 6). 


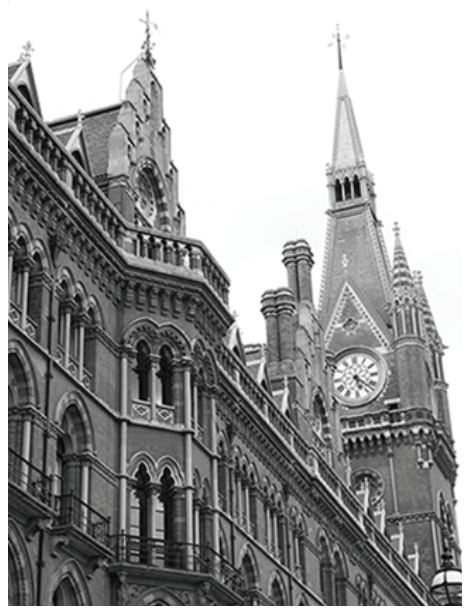

Figura 6. Londres, St. Pancras Renaissance Hotel, antiguo Midland Grand Hotel, Scott 1873 (Foto del autor 2014).

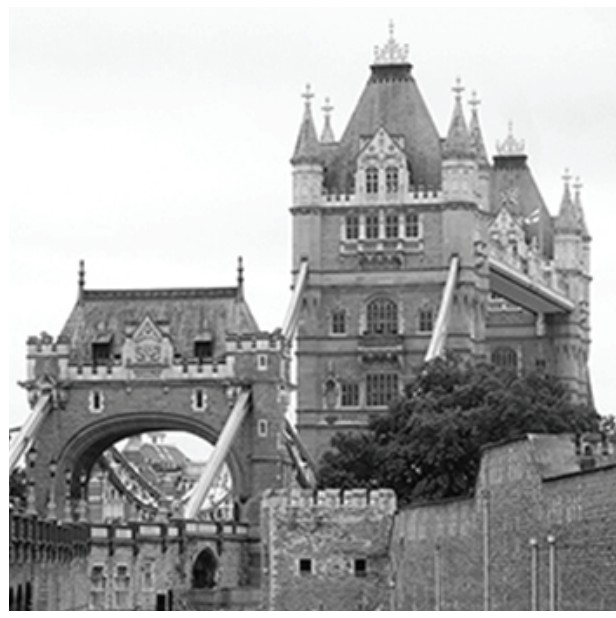

Figura 7. Londres, Tower Bridge, Jones 1894 (Foto del autor 2014)

Y fue este manejo del estilo el que no dejó de tener críticas frente a los más tradicionalistas como el temprano Pugin; Saint (1995, p. 93) manifiesta que "sus sucesores victorianos, como William Butterfield, William Burges, G. E. Street, y otros...alegremente incorporaron cuando les convino, ideas francesas, alemanas o italianas en sus iglesias,...no fue hasta finales del periodo victoriano que hubo un regreso al ideal puramente nacional del estilo arquitectónico." Mientras que Aldrich (1999, p. 188) sostiene que además de William Butterfield, el principal impulso con el que contó el gótico policromado de los años 1850 y 60 fue el de Street.

Se identifica por tanto en la obra de Street la influencia de sus viajes ya no solo en el aspecto estructural de la edificación, sino en los valores dados al repertorio formal en los más variados espacios y detalles arquitectónicos, pudiéndose comparar orígenes y similitudes tomados por ejemplo del gótico italiano con el manejo de la fábrica de ladrillo y del mármol, o de los remates de sus torres y por supuesto de todo el colorido; o en el caso español referido a los pórticos al exterior de los edificios, a las alternativas de las plantas arquitectónicas, o a simples detalles como los obtenidos a través del manejo del hierro forjado por ejemplo en rejas y puertas. ${ }^{6}$

Su forma de trabajar nos recuerda continuamente la importancia del control de las fuentes disponibles para contextualizar el trabajo de campo y poder llegar a conclusiones novedosas. Gracias a su familiaridad con la obra de James Fergusson, y la de Eugène Viollet-le-Duc -de quien aprende a leer la geometría de las bóvedas, especialmente para tratar con el problema del trazado de la gi- 
rola- es capaz de referir constantemente los modelos españoles a los europeos y descubrir lo que caracteriza nuestra historia (Girón, 2015, p. xi).

No deja de llamar la atención que en sus grandes y más representativos proyectos como los Reales Tribunales de Justicia de Londres o la ampliación de la catedral de Cristo de Dublín, se evidencia un Gothic Revival más apegado al tradicional gótico inglés y continental (Ver Figura 8), mientras que en sus proyectos secundarios sobresale la influencia del colorido gótico italiano, por ejemplo en las iglesias de St. James the Less o St. Mary Magdalene, ambas en Londres (Ver Figura 9).

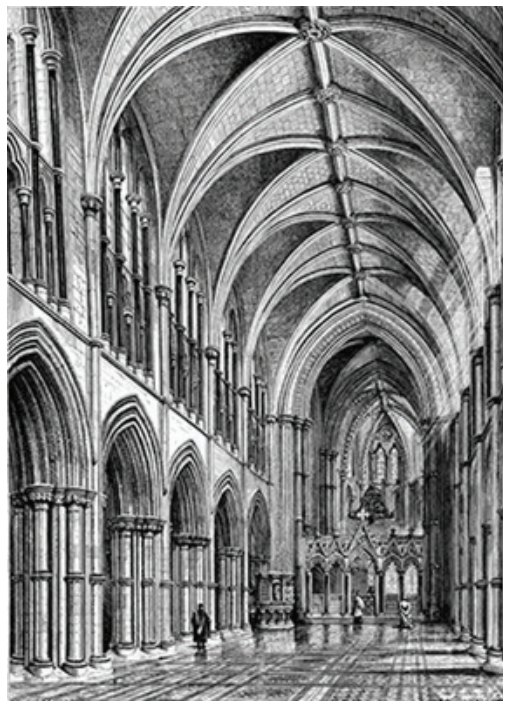

Figura 8. Dublín, catedral de Cristo, restauración y reforma de G. E. Street, 1871-8 (Street, 1882).

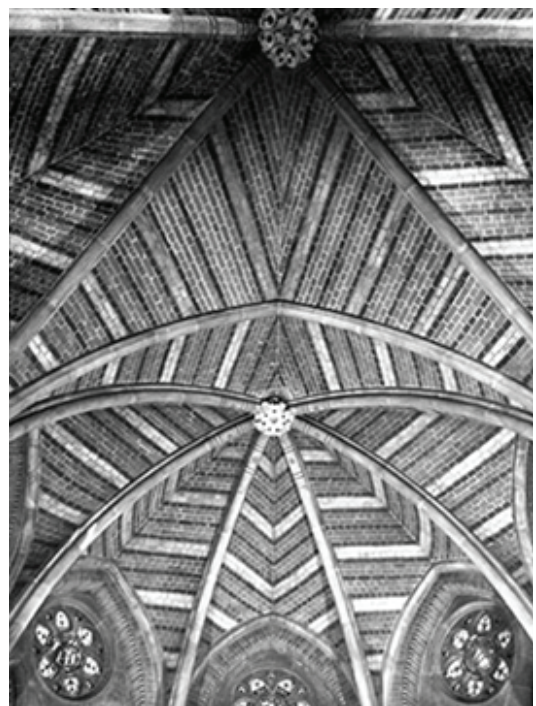

Figura 9. Londres, iglesia de St. James the Less, interior del ábside, diseño de G. E. Street, 1861 (López,2015, p. xxix).

El refuerzo dado por Street a su obra en cuanto a origen, estructura, forma y función nos lleva a pensar en el concepto de una cadena armónica formal, como lo explica Pokropek (2018, p. 22) "es obvio que al reforzarse mutuamente las características protagónicas que sostienen la idea o principio de acción enunciado como argumento formal, este se vuelve más definido o inteligible." Una inteligibilidad transmitida de forma coherente, que es lo que ha permitido dar un valor distinto a la obra de Street, no necesariamente un valor mayoritariamente aceptado ni para la sociedad actual, ni para la sociedad de entonces, que ante la prosperidad victoriana se decantaba por un deseo incesante de modernidad, receptiva más bien como se señaló más arriba, con una arquitectura más comercial y de espectáculo, pero asimismo muy apegada al estilo gótico como un referente nacional de 
estilo, en la que no necesariamente se podría establecer una cadena armónica formal, pero si una relación con una aproximación, no carente de valor frente a la anterior, es decir una versión, no el conocimiento tácito, como lo explica Pokropek (2018, p. 22), "conocer es una construcción en la que participamos de forma activa, a través de procesos de composición, descomposición, ponderación, ordenación, supresión, complementación y deformación. Cada aproximación consistiría, entonces, en una versión de mundo."

\section{El caso de los Reales Tribunales de Justicia de Londres}

La obra que consagró a Street en el Reino Unido fue el monumental palacio londinense de los Reales Tribunales de Justicia 'The Royal Courts of Justice," un edificio en el cual conjugó todo cuanto investigó sobre el gótico, llegando a constituirse en una obra emblemática del Gothic Revival (Ver Figuras10 y 11), que lamentablemente Street no llegó a ver concluida por su prematura muerte, atribuida a la sobrecarga de trabajo y a la presión por concluirla, y que le ocupó buena parte de sus preocupaciones en la última etapa de su vida, comenzando desde el mismo concurso para su diseño y ejecución en el cual no hubo ningún ganador, y a toda la polémica desatada porque sin embargo, ya fuera de concurso, le fue adjudicada con un diseño distinto al que presentó al concurso. ${ }^{8}$

Ésta adjudicación le supuso muchas críticas y fue el objeto de la mirada acusadora de sus colegas, ya que la importancia del edificio y toda su carga simbólica le ubicaron ante un panorama polémico con un fuerte seguimiento mediático, que Street supo sortear debido a su fuerte personalidad y a su militancia en varios círculos académicos y profesionales, que junto a su ferviente activismo, le permitieron contar con varios mecanismos de defensa y de opinión, llegando finalmente a ser reconocido por su trabajo que lo consagró como uno de los más destacados e influyentes arquitectos del siglo XIX. ${ }^{9}$

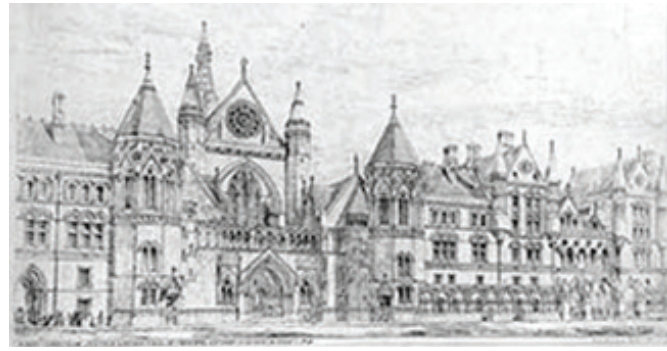

Figura 10. Londres, Royal Courts of Justice, dibujo de G. E. Street, 1871

(Bingham 2011)

La polémica más allá del concurso, había surgido por el diseño que se esperaba del edificio, y como otros concursantes y personajes consideraban que éste debía tener para representar un verdadero sentido del Gothic Revival, sobre la base un asentado carácter nacional del estilo gótico, que tras lógicos paréntesis de otros estilos, prácticamente había 
marcado hasta entonces la historia arquitectónica del Reino Unido y cuya influencia se había esparcido por todas sus colonias de ultramar.10

Hubo de hecho dos famosos arquitectos del Gothic Revival que se excusaron de participar en el concurso debido a la limitación de libertad en el manejo del Gothic Revival, ellos fueron T. H. Wyatt y P. C. Hardwick, mientras que John Gibson abandonó el concurso. Entre otros arquitectos participantes se encontraban los afamados George Gilbert Scott, H. F. Lockwood, Raphael Brandon, William Burges, J. P. Seddon, Alfred Waterhouse y E. M. Barry (Summerson, 1970, p. 12).

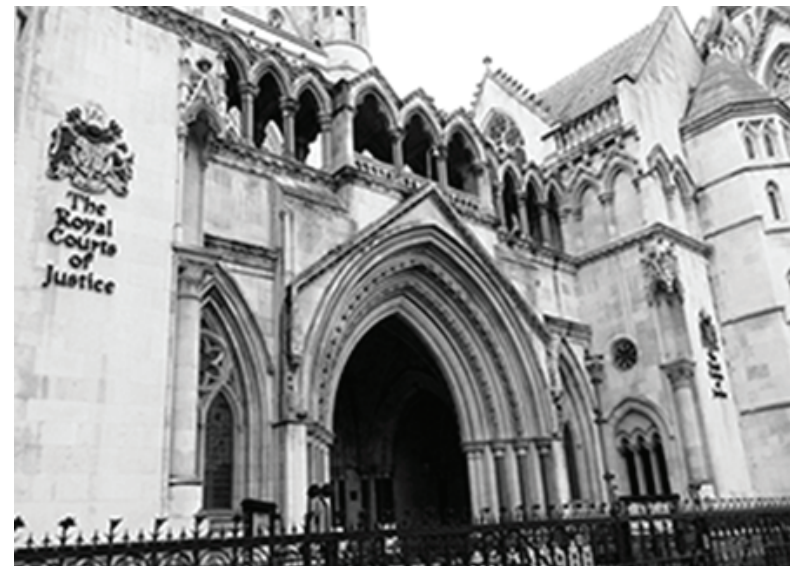

Figura 11. Londres, The Royal Courts of Justice, G. E. Street 1882 (Foto del autor, 2014)

El mérito para unos y el desmérito para otros sobre el diseño de Street, se esbozaba en cómo él había conjugado una serie de elementos no solo del gótico inglés sino del conjunto del gótico europeo, aspecto que para los más tradicionalistas no representaba el verdadero sentido nacional del diseño gótico, y que estaba patentizado en los más diversos aspectos de la composición arquitectónica del edificio, desde la organización y distribución de espacios y volúmenes hasta los más mínimos detalles, que además suponía una aplicación estructural basada en los antiguos edificios góticos.

El concurso tuvo un carácter ambiguo y paradójico, ya que había una generación de arquitectos que practicaban en el entorno tecnológico más avanzado del mundo y que, sin embargo, estaban comprometidos, con diversos grados de intensidad, en la promoción de los estilos medievales de la arquitectura. En su juventud se habían quedado atrapados en una revolución del gusto que tuvo el efecto de separarse casi por completo de las tradiciones arquitectónicas de su propio país y de Europa (Summerson, 1970, p. 18). 
Inexcusablemente en el palacio de los Reales Tribunales de Justicia de Londres se identifica la influencia de los viajes de Street, aunque Scott llegó a decir que la obra arquitectónica de Street no era digna de su talento, ante lo cual Summerson (1970, p. 12) comenta que "sin embargo no fue la opinión general y obviamente fue su arte superior el que le aseguró el encargo del diseño del Palacio de los Tribunales de Justicia de Londres." Las palabras de Scott respondían evidentemente a su protagonismo, ya que para entonces se perfilaba como favorito para ganar el concurso, no solo por su propia valía como arquitecto del Gothic Revival, sino también por su poder económico y su influencia, al estar al frente del estudio inglés de arquitectura más grande de la época.

No obstante otros arquitectos protagónicos se presentaron también con proyectos ajustados a las bases del concurso, no en vano se trataba de erigir un importante edificio, localizado a su vez en uno de los sititos más emblemáticos de Londres. "Algunos concursantes, como Scott y Barry, se aferraron más bien furtivamente a los viejos principios clásicos, comparándolos con el arte. Otros, Street y Burges, trabajaron como alquimistas que intentaban hacer un gótico moderno y moderno al gótico" (Summerson, 1970, p.18). Sobre esta apreciación, Aldrich(1999, p. 197) recuerda la influencia de Street en las nuevas generaciones de arquitectos, haciendo referencia a la obra de Richard Norman Shaw, "un grupo de jóvenes arquitectos diseñadores que practicaron en la oficina de G. E. Street iban a cambiar el énfasis del medievalismo arqueológico a uno de sentido más general de forma medieval. Entre ellos estaba Richard Norman Shaw."

Los prolegómenos del concurso para el diseño de los Reales Tribunales de Justicia han quedado en la historia señalados con varios adjetivos, pero el resultado finalmente se impuso como un modelo con un sentido de orden, con una dialéctica que dio como resultado una versión coherente del gótico sustentada en una metodología de investigación.

No pasaron muchos años antes de que el concurso para los Tribunales de Justicia fuera visto como un fiasco espantoso,... hoy lo vemos como un pequeño y extraño remolino en las mareas de la carrera de la historia del siglo XIX. Pero de cara a los diseños, vemos un poco más: ejes valientes de energía, destellos de brillantez visionaria, que llegan a nuestro tan diferente mundo de libertad de estilo (Summerson 1970, 18).

Street dejó una numerosa obra construida, con un intercambio de influencias no solo importadas a las islas británicas desde el continente, sino también al contrario, es decir un intercambio de ideas para sus obras al exterior, como lo señala Germann (2009, p. 284) en el caso de la iglesia Anglicana de Lausana en donde Street se valió del estilo gótico inglés, preguntándose hasta que punto, que es lo inglés y que es lo suizo, clasificando a sus diseños como: 1. estilo urbano - estilo rural; 2. modelos locales - modelos extranjeros; 3. copia arqueológica - estilo personal; y 4. construcción simple y aparente - composición pintoresca (Germann, 2009, p. 294).

Para finalizar cabe mencionar que en cuanto al sello personal de Street en el campo del diseño interior y de mobiliario, y volviendo al palacio de los Reales Tribunales de Justicia de Londres, es allí donde quedó plasmada toda su creatividad al ocuparse él mismo del diseño de puertas, accesorios, rejas y mobiliario, y en donde por supuesto no pudieron faltar 
las referencias al conjunto del gótico europeo. Una actividad sobre la cual se llegó a decir que Street se anticipó a los diseñadores del movimiento Arts and Crafts y que de hecho fue su despacho el vivero de dicho movimiento (Victorian Church Art, 1972, p. 46). Y si de anticiparse a otros arquitectos se trata, se podría encontrar similitudes entre su diseños de rejas y remates de torres para los Reales Tribunales de Justicia (Ver Figura 12), muy cercanas al Art Nouveau y sus derivaciones, como lo fue la propia intención de explicar la razón del gótico en cuanto al comportamiento del arco apuntado, que años más tarde sería un sello distintivo en la obra Gaudí.

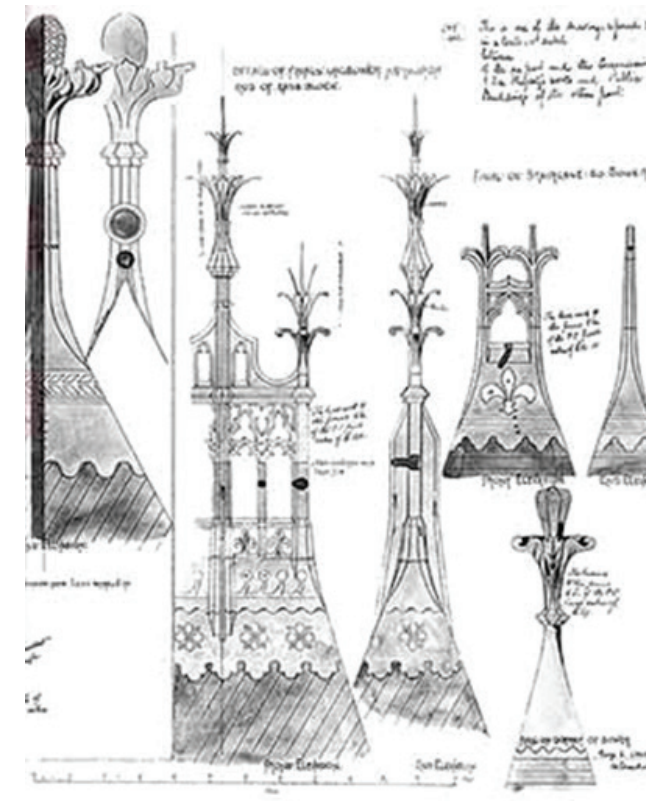

Figura 12. Londres, Royal Courts of Justice, remates de torres (Brownlee, 1984).

\section{Conclusiones}

El valor dado por Street al comportamiento estructural de los edificios góticos y su consecuente aplicación en el Gothic Revival ha quedado como un valor arraigado en su obra. Los recursos tomados del conjunto del gótico continental y del gótico inglés o como él dice, el también llamado viejo estilo inglés, a partir del cual propuso un manejo de las formas adaptándolo a los nuevos espacios de la vida cotidiana en todos los órdenes, marcan su importancia y su sentido lógico, respondiendo precisamente a la labor de un profesional que enriqueció sus conocimientos con la investigación, y cuya formación profesional y práctica había transcurrido en medio de viajes de análisis de arquitectura gótica. 


\section{Notas}

1. August Welby Northmore Pugin se consolidó entre los arquitectos neogóticos como uno de sus ideólogos, y como uno de los más hábiles y completos creativos, ya que incursionó no solo en la arquitectura con numerosa obra civil y religiosa, sino también en el diseño de objetos y todo lo relacionado con las artes decorativas del Gothic Revival (López, 2016, p. 42).

2. Street planificó para la iglesia Anglicana varios templos en Suiza, Turquía, Italia y Francia, e intervino en la restauración de algunos templos católicos, por ejemplo en Francia en las catedrales de Reims y Chartres (López, 2015, p. xxvi). Entre sus proyectos más reconocidos fuera del Reino Unido están las iglesias de AllSaints de Roma, la iglesia Anglicana de Lausana y la Crimean Memorial de Estambul.

3. Robert Willis fue quien introdujo el estudio del gótico y cuya terminología apareció a la vez con la necesidad de precisión del dibujo. Willis y Whewel forman parte de una generación anterior a Street, coincidentes en su labor científica respecto al gótico, y también respecto a su activismo en Cambridge, forjándose una amistad entre ambos...Continuando con la tradición del Grand Tour, Willis realizó varios viajes a Francia, Alemania e Italia, de cuyas memorias saldrá su conocido libro Remarks on the Architecture of the MiddleAges, Especially of Italy, una obra que se adelantó en el estudio de la arquitectura gótica italiana (López, 2016, p. 20).

4. La revista The Ecclesiologist fue el órgano difusor de la Ecclesiological Society en donde Street participó desde muy joven, con un registro de su actividad a través de numerosos artículos, correspondencia y varias noticias.

5. Véase un completo estudio comparativo de obras de Street, en (Hitchcock, 1960).

6. Véase varios análisis comparativos de detalles constructivos en (Jackson, 1980), (Jackson, 2011), (Germann, 1972) y (Gubler y Davies, 1976).

7. A Street se le encargo el diseño de los Reales Tribunales de Justicia de Londres tras un concurso realizado entre 1866 y 1867. Para su generación, los tribunales de justicia tenían una importancia simbólica y real, casi igual a la que tenían las Casas del Parlamento para los primeros victorianos (Brownlee, 1984, p. 17).

8. "hubo once concursantes, y aunque Street no lo ganó, el gobierno le adjudicó el proyecto. Street para entonces tenía 42 años y el edificio que diseñó fue distinto al edificio con el que concursó" (Summerson, 1970, p. 14).

9. La actividad profesional y académica de Street estuvo ligada a un notorio activismo en los distintos círculos que frecuentó, principalmente en la Ecclesiological Society, de cuyas sesiones y debates desde su temprana militancia, queda en su revista un innumerable registro de su actividad, además de otros artículos y correspondencia publicados en libros y otras revistas.

10. El concurso para los Tribunales de Justicia, como el concurso para las Oficinas de Gobierno, fue arruinada por la intrusión del problema del estilo; el jurado estuvo intimidado ante el acto de elegir entre un estilo artístico y un proyecto conveniente, al igual que los arquitectos estaban molestos en sus intentos de unir a los dos (Summerson, 1970, p. 18). 


\section{Lista de Referencias Bibliográficas}

Aldrich, M. (1999). Gothic Revival. London: PhaidonPress Ltd.

Bingham, N. (2011). Masterworks: Architecture at the Royal Academy of Arts, London: RA. Brownlee, D. (1984). The Law Courts: The Architecture of George Edmund Street. New York, Cambridge: Architectural History Foundation, MIT Press.

Germann, G. (1972).“G. E. Street and Switzerland,” en ZeitschriftfürSchweizerischeArchä ologieundKunstgeschichte, vol. 29, No 2 y 3, Zurich: SchweizerischesNationalmuseum, p.118-130.

. (2009). Aux origines du patrimoinebâti, Gollion-Suisse: Infolio.

Girón, F. (2016). Prólogo, en George E. Street, La arquitectura gótica en España, F. S. López Ulloa (ed.), Madrid: Instituto Juan de Herrera, pp. ix-xii.

Gubler, J. e I. Davies. (1976). "Street and Viollet-le-Duc," en The Architectural Review, Sep., vol. CLX, No 955, London: The Architectural Press Ltd., p. 189.

Hitchcock, H. R. (1960). “G. E. Street in the 1850's," en The Journal of the Society of Architectural Historians, vol. 19, no. 4, Chicago: Society of Architectural Historians, pp. 145-71.

Jackson, N. (1980). “The Un-Englishness of G. E. Street'sChurch of St James-the-Less," en Architectural History, vol. 23, London: SAHGB PublicationsLimited, pp. 86-94,191-5.

Jackson, N. (2011). "George Edmund Street (1824-81): AnArchitect on Holiday," en Episodes in the Gothic Revival SixChurch Architects, Christopher Webster (ed.), Reading: SpireBooksLtd, pp. 163-98.

López Ulloa, F. S. (2009). “George Edmund Street (1824-1881) y su contribución al estudio de la Arquitectura Gótica en España," en Actas del Sexto Congreso Nacional de Historia de la Construcción, Valencia, 21-24 de octubre de 2009, Santiago Huerta et al (ed.), Madrid: Instituto Juan de Herrera, pp. 789-801.

. (2010). "The Theory and Practice of Restoration in England in the Second Half of the 19th Century: The Work of George E. Street," en Advanced Materials Research, vols. 133-4, Switzerland: Trans Tech Publications, pp. 1045-50.

. (2015). “George E. Street, su vida, su legado y la arquitectura gótica española," en George E. Street, La arquitectura gótica en España, F. S. López Ulloa (ed.), Madrid: Instituto Juan de Herrera, pp. xvii-lv.

. (2016). Las teorías del gótico y su representación gráfica en España en el último tercio del siglo XIX. Un estudio sobre SomeAccount of Gothic Architecture in Spain, de George Edmund Street, Tesis Doctoral, Madrid: Universidad Politécnica de Madrid.

López Ulloa, F. S. y F. J. Girón. (2014). “Los dibujos de arquitectura gótica española de George E. Street," en El dibujo de viaje de los arquitectos. Actas del 15 Congreso Internacional de Expresión Gráfica Arquitectónica. Las Palmas de Gran Canaria, del 22 al 23 de mayo de 2014, A. Melián (ed.), Las Palmas de Gran Canaria: Universidad de las Palmas de Gran Canaria.

Pokropek, J. (2018). “Lógicas de coherencia para la interpretación y producción del diseño interior y sus criterios de selección de formas objetuales," en Cuadernos del Centro de Estudios en Diseño y Comunicación, Cuaderno 81, Buenos Aires: Universidad de Palermo. 
Pugin, A. W. (1836). Constrastsor, a parallelbetween the noble edifices of the fourteenth and fifteenthcenturies, and similar buildings of the presentday; shewing the presentdecay of taste, London.

Saint, A. (1995). "Pugin's Architecture in Context," enA. W. N. Pugin: Master of Gothic Revival. New Haven - London: Yale University Press, pp. 79-102.

Stamp, G. (2003). "High Victorian Gothic and the Architecture of Normandy," en Architectural History, vol. 62, no. 2, Jun., London: SAHGB PublicationsLimited, pp. 194-211.

Street, A. (1888). Memoir of George Edmund Street, R.A., 1824-1881. London: John Murray.

Street, G. E.(1853). "On the revival of the ancientstyle of domesticarchitecture," en The Ecclesiologist, vol. XIV, no. XCV, London: The Ecclesiological Late Cambridge Camden Society, pp. 70-80.

. (1855). Brick and Marble in the MiddleAges: Notes of a Tour in the North of Italy, London: John Murray.

. (1865). SomeAccount of Gothic Architecture in Spain, London: John Murray.

. et al. (1882). The Cathedral of the Holy Trinity, commonly called Christ Church Cathe-

dral, Dublin: anaccount of the restoration of the fabric, London: Sutton Sharpe and co.

Summerson, J. (1970). “The law Courts competition of 1866-67," en RIBA Journal, january 1970, London: RIBA.

Victorian Church Art. (1971).Victorian Church Art, ExhibitionNovember 1971 - January 1972, Victoria \& Albert Museum, London: Victoria \& Albert Museum.

\begin{abstract}
George E. Street (1824-1881) is considered one of the most outstanding designers of Gothic Revival during the splendor of the United Kingdom in Victorian times, with GG Scott, W. Butterfield, or W. Burges. He represented through his prolific work, a period charged with symbolism around a canonical style with a marked religious accent that Pugin considered as an ideal of nation. Therefore, he was subject to opinions that defended, on the one hand, the purist sense in the management of style, related only to the influence of English Gothic, and on the other hand, the inclusion of some continental influence related to the rest of Europe. A style that not only had to do with the strict sense of its application to a new work, but also in how it was applied in the innumerable reforms, extensions and restorations of which an infinity of Gothic buildings were object. To this extent, the present investigation delves into the stylistic resources handled by George E. Street and how his work was consecrated not only in the field of architectural design but also in the design of furniture and accessories.
\end{abstract}

Keywords: Gothic Revival - George E. Street - Gothic Restoration - Gothic Architecture - Morphology.

Resumo: George E. Street (1824-1881) é considerado um dos principais designers do Gothic Revival durante o esplendor econômico na era vitoriana UK com GG Scott, W. Butterfield, ou W. Burges e representou, através do seu trabalho prolífico, uma época rica em 
simbolismo em torno de um estilo canônico de marcado acento religioso considerado por Pugin como um ideal de nação. E, portanto, esteve sujeito a opiniões que defendiam o sentido purista no estilo de gestão, relacionadas apenas com a influência do Gótico Inglês, e, por outro lado, aquele que incluiu a influência continental conectado com o resto da Europa. Um estilo relacionado com o estrito sentido de aplicação a uma obra nova e em como aplicava-se nas reformas, ampliações e restaurações que sofreram muitos edifícios góticos. Nessa medida, a presente pesquisa adentra-se nos recursos estilísticos desenvolvidos por George E. Street e como sua obra se consagrou no âmbito do design arquitetônico e no design de móveis e acessórios.

Palavras chave: Gothic Revival - George E. Street - Restauração gótica - Arquitetura gótica - Morfologia.

[Las traducciones de los abstracts fueron supervisadas por el autor de cada artículo] 